\title{
La pedagogía de Don Bosco y de los salesianos
}

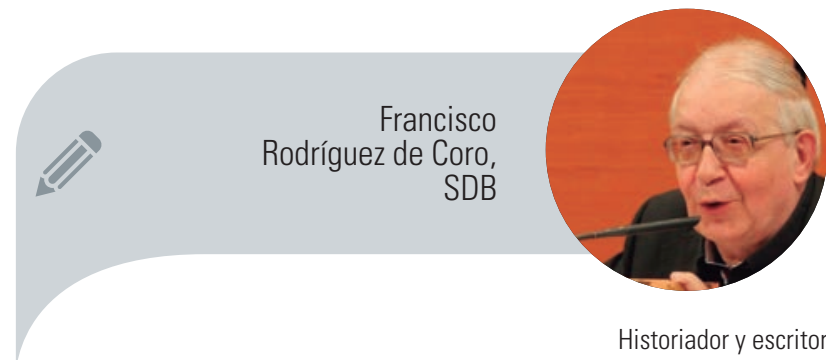

\section{Perfil de san Juan Bosco}

Juan Bosco nace el 16 de agosto de 1815 en un pequeño pueblo del Piamonte, Castelnuovo d'Asti. Hijo de Francisco Bosco y Margarita Occhiena, tuvo una infancia dura al quedarse huérfano en 1817. Sin embargo, la figura y la personalidad de su madre, que le influyó toda la vida, le ayudan a forjar un carácter afable.

En 1835 ingresa en el seminario de Chieri, donde realiza los estudios de filosofía y teología, siendo ordenado sacerdote el 5 de junio de 1841. Por indicación de su confesor, don Cafasso, se traslada a Turín para ampliar estudios de teología moral en el Convitto eclesiástico, siendo tan interpelado por la situación de los muchachos en calles y cárceles que funda su Oratorio en 1842 con Bartolomé Garelli, huérfano de padre y de madre.

Después de unos años de itinerancia, compartido como capellán de las obras asistenciales de la marquesa Barolo, establece su Oratorio en Valdocco, a las afueras de Turín, que progresivamente se abre en colegio, internado, talleres y otros dos oratorios en el mismo Turín. En 1854 elige entre sus muchachos cuatro de ellos como primer germen de los salesianos; $y$ en 1859, con la bendición de Pío IX, funda la Congregación Salesiana, que al llegar en 1874 la aprobación cuenta ya con 330 discípulos.

Publicado su libro El sistema preventivo en la educación de la juventud -abierto, avanzado y propio, vale la pena, por tanto, una visita-, abre sus primeras casas en Argentina y Francia, inaugurando en España su primer centro en Utrera (Sevilla) en 1881 y en Madrid-Salesianos Atocha en 1899, ya con su primer sucesor. Miguel Rua, hoy beato.

Fallece el 31 de enero de 1888, después de tres viajes en olor de multitudes, uno a París en 1883, otro a Barcelona en 1886 y, en fin, otro a Roma en 1887. Canonizado en 1934 por Pío XI, san Juan Bosco es una de las Ilaves -su valor, de ahí- para comprender una época aún nuestra.

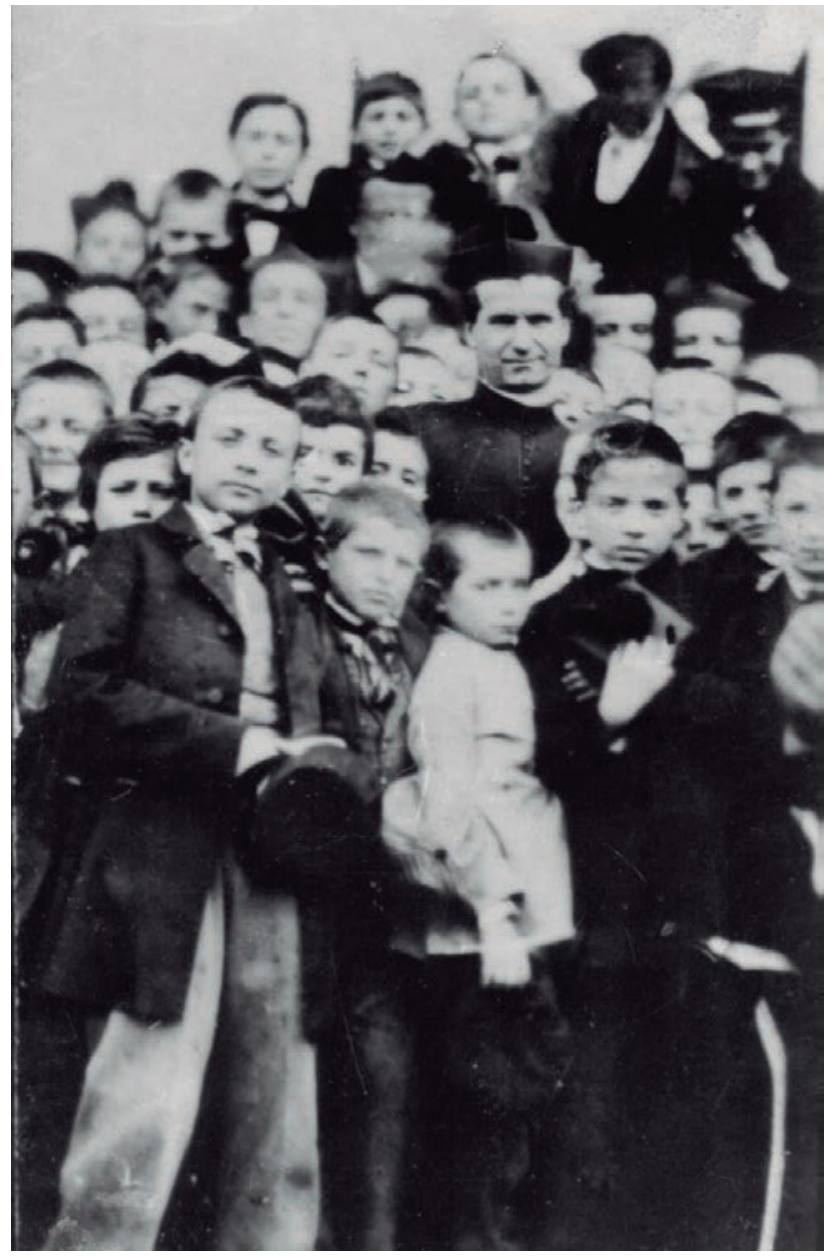

\section{Una pedagogía adaptada a los muchachos. Introducción}

La pedagogía de Don Bosco, centrado en la caridad pastoral (Constituciones 10), se encarna y se manifiesta en la experiencia educativa del santo en el Oratorio de Valdocco-Turín, que él Ilamó Sistema Preventivo. Bravo y decidido luchador por la causa de todas las novedades morales y pedagógicas, y muy especialmente por la revolución (conseguida) de la pastoral y la espiritualidad, que su movimiento acarreaba, le volvieron decididamente innovador y moderno sin pretenderlo.

Queremos subrayar que el santo, moviéndose con la más refinada naturalidad, en su sistema pedagógico, ofrece una triple realidad dinámica, interrelacionada: un impulso pastoral, es decir, un proyecto educativo integral; una pedagogía como propuesta de vida cristiana y un método práctico. 


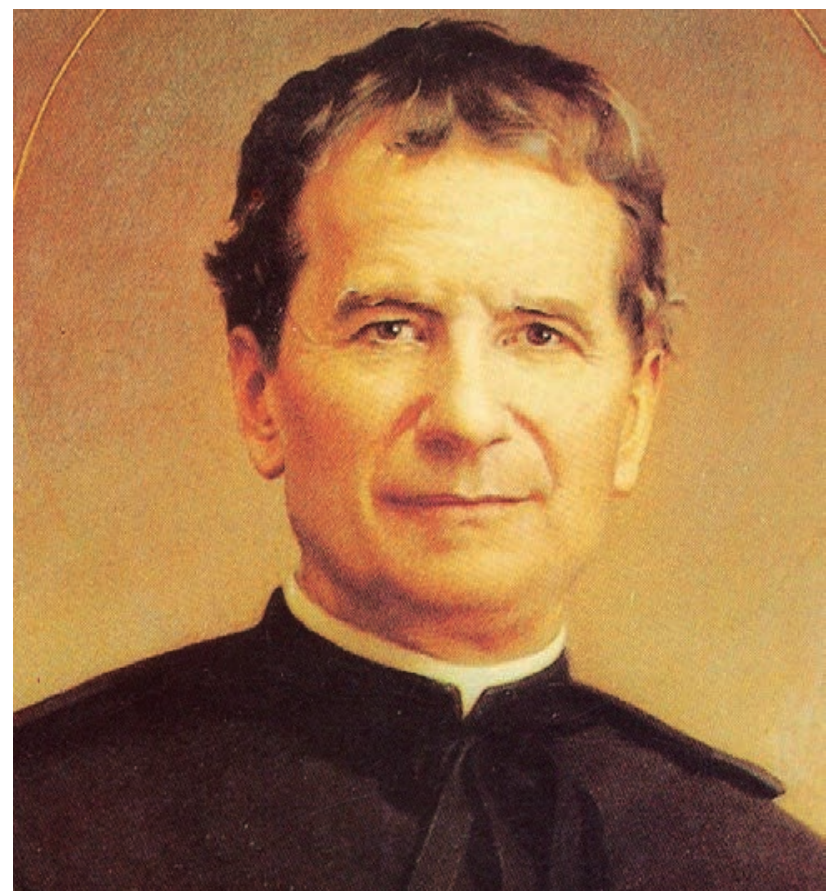

Fuente: Wikimedia

Las raíces más fuertes en su pensamiento y convicciones nos llevarían lejos. Pero de su pasión por lo clásico y tradicional de la escuela de espiritualidad española del siglo XVI y la escuela italiana del XV y del XVI, extrae su realización individual y los argumentos del camino de sus oratorios. San Ignacio de Loyola, san Francisco de Sales -que dará nombre a sus discípulos-, san Felipe Neri, san Vicente de Paúl y san Alfonso María de Ligorio sitúan su verdadera pedagogía, dentro de la vida cotidiana de educadores y educandos. Conectado con ellos, pluralmente, la historia de su pedagogía es la historia de un éxito.

El gran acierto del "Padre y Maestro" de la juventud, declarado así por san Juan Pablo II, fue la mezcla de la cotidianidad y el biografismo entrelazados con el humanismo cristiano y los arquetipos de Pío IX y León XIII.

\section{Pedagogía de la amistad}

El primer don que san Juan Bosco ofrece a sus discípulos y a sus muchachos es una relación humana serena y abierta. El dominio de sí mismo, elaborado en profundidad, le permite ofrecerse a los demás de manera sutil y eficaz, en un cauce pastoral, sobre todo.

Dentro de esta perspectiva, son dos los aspectos que más sobresalen de la humanidad del santo pedagogo. Primero, un afecto intenso. Su segundo sucesor, Pablo Albera, lo recuerda así:

Debo decir que Don Bosco nos quería como nadie, de manera única: ejercía sobre nosotros una atracción irresistible. Yo me sentía como prisionero de una fuerza afectiva que se apoderaba de mis pensamientos, palabras y obras. Me sentía querido como nunca me había querido nadie, era algo especial, por encima de todo cariño. Nos envolvía a todos por completo una atmósfera de alegría y felicidad. [...] Y no podía ser de otro modo, porque, de cada una de sus palabras y obras, brotaba la santidad de su unión con Dios que es la caridad perfecta. Y nos atraía hacia sí mediante la plenitud del amor sobrenatural que le abrasaba el corazón. De esta singular atracción brotaba esa acción que conquistaba nuestros corazones. Los múltiples dones naturales que tenía se habían trocado en sobrenaturales por la santidad de su vida.

Y al afecto, hay que añadir su talante constante de amistad. Muy diversas y variadas fueron sus amistades, desde pequeño, adolescente y joven hasta su madurez. Señala uno de sus sucesores, Juan Vecchi:

Cultiva la amistad con sacerdotes, religiosos, cooperadores y jóvenes, escritores, perseguidos, políticos, autoridades. Lo dejará documentado en una serie de recomendaciones de este tenor: Haz de modo que todos aquellos con quienes hables se hagan amigos tuyos. La amistad será un tema de su pedagogía.

\section{Pedagogía de lo cotidiano}

Resulta fácil definirse como cristiano de forma teórica, pero no tanto en lo concreto del día a día, abriéndose a las exigencias de las bienaventuranzas. Esta experiencia requiere en la persona el don de la unidad.

Cuando nos acercamos a la figura de Don Bosco, destaca este don de la unidad; es decir, una humanidad en total armonía con la santidad. "Su humanidad es la manifestación de su santidad, al tiempo que esta parece como el esplendor de su humanidad" (VECCHI). El texto constitucional de los salesianos lo recoge así, en su artículo 21:

El Señor nos ha dado a Don Bosco como padre y maestro. Lo estudiamos e imitamos admirando en él una espléndida armonía entre naturaleza y gracia. Profundamente humano y rico en las virtudes de su pueblo, estaba abierto a las realidades terrenas; profundamente hombre de Dios y lleno de los dones del Espíritu Santo, vivía como si viera al Invisible. Ambos aspectos se fusionaron en un proyecto de vida fuertemente unitario: el servicio a los jóvenes. Lo realizó con firmeza y constancia, entre obstáculos y fatigas, con la sensibilidad de un corazón generoso: no dio un paso, ni pronunció palabra, ni acometió empresa que no tuviera por objeto la salvación de la juventud. Lo único que realmente le interesó fueron las almas.

Es decir, tal talante llevaba a Don Bosco a valorar el día a día, lo cotidiano y a

[...] proponer una verdadera escuela de trabajo, donde se sigue una pedagogía del deber que educa en la forma práctica de vivir la espiritualidad (CGXXIV, 28). Sin rodeos, a la base de tal consideración se sitúa el misterio central del cristianismo, el de la Encarnación, como lugar preferido para encontrar a Dios, precisamente en la realidad humana: "Os 
aseguro -certificaban los salesianos capitulares- que cada vez que lo hicisteis con uno de estos mis humildes hermanos, conmigo lo hicisteis.

(MT 25,40)

Por consiguiente, es la vida humana la que nos introduce en el acontecimiento de la Encarnación, como paso obligado para descubrir y amar lo cotidiano como realidad nueva donde Dios actúa como padre que previene, acompaña y precede.

\section{Pedagogía de la alegría}

Una de las características que llama más la atención en la pedagogía de Don Bosco es su actitud, constante y perseverante, de la alegría. La alegría en él significa muchas cosas: el profundo sentido del bien y la convicción total de que este es más fuerte que el mal, la confianza en las personas (hay mucha bondad en el ser humano), el singular interés por los hechos de cada día como expresión de la voluntad de Dios y cómo la vida suele ser lo que jamás resulta; también la alegría es la acogida matizada de valores novedosos. Asumida, honda y tan de veras fue su alegría que la venía a identificar con la santidad. En la biografía que escribió de uno de sus alumnos, hoy santo, Domingo Savio, pone en labios de él las palabras que le dirigió a un nuevo llegado al colegio: "Nosotros aquí hacemos consistir la santidad en estar alegres" (CANALS 186).

Asimismo, para Don Bosco el arranque y el impulso de esa alegría debe ser Dios, el Dios revelado en Jesucristo ("Como es Jesús, así es Dios" dice el teólogo Rojano, 2018), de ahí su insistencia en los sacramentos. El horizonte de cualquier vida debe seguir siendo una esperanza, el cambio radical (la conversión), un aliciente. Siendo todavía adolescente, fundó la Sociedad de la Alegría entre sus propios condiscípulos; desde que inicia la obra de sus oratorios o colegios, quiere que se conviertan todos en una sociedad de la alegría (casa, colegio, taller, iglesia y patio), en la que a los muchachos se les dé "amplia posibilidad de saltar, correr, gritar a placer", siguiendo así las recomendaciones de san Felipe Neri, uno de sus modelos: "Haced todo lo que queráis, a mí me basta con que no cometáis pecados" (Bosco, Escritos 2012). Bien entendido y con datos que nos llevarían lejos, para Don Bosco la alegría no está reñida con la ascesis. Cierto es que nunca buscó la mortificación por sí misma, pero la vivió desde pequeño en su casa y la contagió entre sus seguidores, a los que a veces tuvo que atemperar.

¿Don Bosco se pretendió un asceta? No, de ninguna manera. Se pretendió un comunicador de vida
Juan Bosco

\section{El sistema preventivo en la educación}

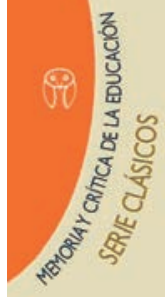

Memorias y ensayos

Edición de José Manuel Prellezo Garcia

Biblioteca Nueva

y de ideas vividas, un recreador de intensidades, un vitalista, adobado con ingredientes propios, personales, eficaces, directos. De hecho, fue un fundador. Es bien sabido que su obra despertaba continuadores. Sus muchachos, Ilanamente, le compraban. Y sin disimulo

\section{Pedagogía de religiosidad popular}

La pedagogía que Don Bosco vive y ofrece, es vivacísima, atrapadora, por su sencillez, en lo que se refiere a las prácticas de piedad. Las recomendaba por activa y por pasiva, las comunes en su ambiente, a excepción de lo que él Ilamó ejercicio de la buena muerte (una vez al mes ponerse en punto de muerte, una especie de retiro, pero como ejercicio escolar), al que él siempre concedió gran importancia, pautado por un librito que se usó primero en el oratorio donde él empezó. El joven cristiano y después en todos los demás. Así pues, la vida religiosa que promociona el santo se iba articulando en un sistema atinado de prácticas comunes, las sugeridas por el catecismo diocesano de Turín y de otras diócesis del Piamonte. Nos referimos a las sencillas oraciones de la mañana y de la tarde, la misa, "en la que se recitaba el rosario", la visita al Santísimo y, sobre todo, la frecuencia de los sacramentos (StelLA, 1968). En su opúsculo sobre su sistema educativo, que él denominó Sistema Preventivo (prevenir antes que curar) escribía: 


\section{0 frases de Don Bosco reflejadas en la película Wonder}

La cinta, basada en la novela del mismo nombre de Raquel Jaramillo Palacio, muestra unas curiosas coincidencias con el sistema preventivo del fundador de los Salesianos.

El pasado mes de diciembre, llegó a las carteleras de los cines españoles Wonder. La película cuenta la historia de Auggie Pullman, un niño con una deformación facial que, tras superar varias intervenciones quirúrgicas y recibir clases desde pequeño en su casa, se enfrenta por primera vez al reto de asistir a una escuela.

El filme, al igual que la novela original, aborda el problema del acoso escolar. Llama la atención la semejanza entre la moraleja de varias historias de la película y el sistema preventivo de Don Bosco. Estas diez frases del fundador de los Salesianos son prueba de ello:

\section{1. "La educación es cosa del corazón"}

Tanto los padres de Auggie como su profesor, el Sr. Browne, demuestran una gran pasión en la labor de educar. Formar personas pasa por poner primero el Amor.

\section{2. "De la sana educación de los jóvenes depende la felicidad de las naciones"}

Cabe destacar el esfuerzo del director del centro, el Sr. Tushman, para que Auggie se sienta acogido desde antes incluso de empezar las clases. También el Sr. Browne apuesta por la integración. El respeto a las diferencias se basa en la convicción de que existe una dignidad común.

\section{3. "Eliminen de una comunidad la murmuración y la parcialidad, y se gozará de una paz perfecta"}

Este consejo de Don Bosco a las comunidades salesianas es aplicable a cualquier grupo humano. Cuando el protagonista de la peli llega a la escuela, se convierte en el centro de las miradas por su aspecto físico. Si los prejuicios se dejan de lado, hay posibilidades de entenderse, tal y como se refleja en el filme.

\section{4. "La dulzura en el hablar, en el obrar y en reprender, lo gana todo y a todos"}

A pesar de su timidez y de las burlas, Auggie no duda en demostrar su compañerismo. Su forma de actuar se corresponde con la máxima escrita por el Sr. Browne en la pizarra para inspirar a sus alumnos: "Cuando tengas que escoger entre ser correcto y ser gentil, escoge ser gentil".

\section{5. "Sin sonrisa no es posible demostrar amistad"}

Auggie no se siente animado en los primeros días de clases, pero después el panorama cambia. Jack Will, su primer amigo en la escuela, reconoce que le gusta pasar tiempo con él y que le hace reír.

\section{6. "No basta con amar a los jóvenes; es preciso que se sientan amados"}

La familia de Auggie lo ama con locura. Cuando el pequeño es marginado en la escuela, ellos están ahí para recordarle que es extraordinario. Además, sus amigos se esfuerzan por demostrarle la autenticidad de su amistad. Pero el protagonista de la peli no es el único que necesita sentirse amado. Su hermana Via y la amiga de esta, Miranda, también manifiestan esta necesidad.

\section{7. "Ser bueno no consiste en no cometer ninguna falta, sino en saber enmendarse"}

Uno de los momentos más duros para Auggie es cuando descubre a su amigo Jack Will hablando mal de él con otros compañeros de clase. También su hermana Via sufre por el distanciamiento de su amiga Miranda. Sin embargo, tanto Jack Will como Miranda caen en la cuenta de lo que han perdido, se arrepienten de sus errores y luchan por recuperar la amistad.

\section{8. "En todo joven, aun en el más desgraciado, hay gérmenes de bondad"}

Esta frase esperanzadora de Don Bosco se plasma en la película a través del personaje de Julian, el niño acosador. El director del colegio lo cita junto con sus padres en el despacho para imponerle una sanción por sus ataques a Auggie. Los progenitores demuestran con su actitud la influencia negativa que han ejercido sobre el chaval. No obstante, la escena termina con Julian pidiendo disculpas al Sr. Tushman.

\section{9. "Tristeza y melancolía, fuera de la casa mía"}

Don Bosco pedía estar siempre alegres, y esta parece que es la máxima en la casa de los Pullman. Cabe destacar también el optimismo que irradia Justin, el novio de Via.

\section{0. "Las espinas de la vida se trocarán en flores para toda la eternidad"}

El espíritu de superación es una constante en la película. Auggie sabe que hay que luchar para alcanzar las metas en la vida. Nunca hay que rendirse, porque siempre espera una recompensa.

Manuel Serrano Salazar (periodista)

La confesión y la comunión frecuente y la misa diaria son las columnas que deben sostener el edificio educativo, del cual se quieran tener alejados la amenaza y el palo. No se ha de obligar jamás a los alumnos a frecuentar los santos sacramentos: pero sí se les debe animar y darles comodidad para aprovechar de ellos.

(Bosco, vol. XVIII, 918)

\section{Pedagogía de la confianza}

San Juan Bosco fue ante todo y sobre todo sacerdote católico, formado en seminarios ultrancistas, pero que vivió asediado por las calles de la prerrevolución industrial y nacionalista de la "Nueva Italia", como todos los educadores y formadores paisanos suyos: José Cafasso, Benito Cottolengo, Leonardo Murialdo, por ejemplo.

Convencido de que "la familiaridad engendra afecto y el afecto confianza", pide al educador confiar en los muchachos para hacer posible la confianza de estos en el educador. En la introducción al Reglamento de los salesianos, escribe que "la juventud no es de 


\section{En cada uno, hay un punto accesible}

\author{
al bien y el primer deber del educador
}

es buscar la cuerda sensible del

corazón y hacerla vibrar

por sí perversa... Si sucede alguna vez que ya están dañados a esa edad, es más por inconsciencia que por malicia consumada".

Uno de sus recursos habituales fue la presentación de modelos y testigos a sus muchachos a través de biografías ejemplares escritas por él. En ellas, Don Bosco destaca distintos aspectos de acuerdo con la diferente personalidad de los biografiados (STELLA, 1969). Así, en Luis Comollo, la ascesis; en Domingo Savio, la lucidez de espíritu; en Miguel Magone, la disponibilidad a la gracia de Dios; en Francisco Besucco, el poder de la oración vocal.

El santo fue precursor de muchas cosas, y las escribió, con calidad y con rigor, con personalidad y con estilo. Muy de su época se adelantó a su tiempo. Afirmaba que, en cada uno, hay un punto accesible al bien y el primer deber del educador es buscar la cuerda sensible del corazón y hacerla vibrar (Bosco MB V, 367).

\section{Pedagogía de los "Tres blancos amores"}

En el encuentro que tuvo lugar en Turín el 21 de junio de 2015 entre el papa Francisco y los salesianos, llamó así a los tres amores que Don Bosco inculcó siempre a sus muchachos y a los salesianos. Nos referimos a Jesús Sacramentado, a María Auxiliadora y al Papa. Hijo de la teología de su tiempo, para él, el Papa significa la Iglesia.

Don Bosco, hombre lleno de anhelos, de quimeras, de ideal; luchador contumaz y fragoso, expresó en "sueños" sus cauces pedagógicos, sus apuestas y sus compromisos. Así, en el "sueño" Ilamado por él de las dos columnas (Bosco MV VII, p. 153 ss.), identifica a la Iglesia con una gran nave que, guiada por el papa como gran timonel, padece la amenaza de otras naves que la atacan. Es el momento en que en medio del mar surgen dos columnas a las que esta gran nave tiene que anclarse para no sucumbir, una más alta, la eucaristía, y otra un poco más baja, la Virgen María, auxilio para vivir la fe en "tiempos recios".

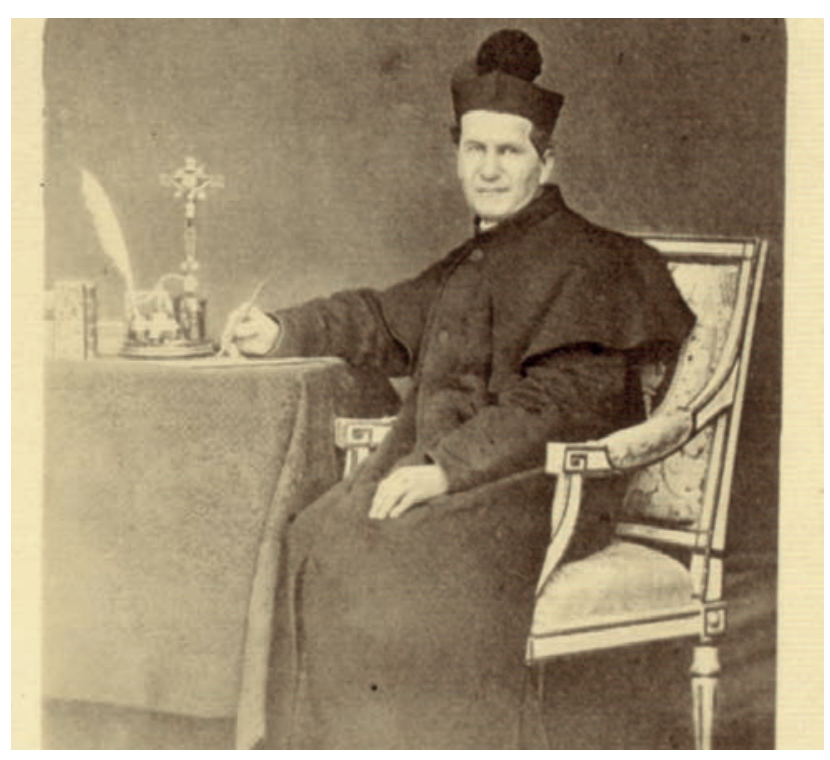

Fuente:Wikimedia

\section{Conclusión}

En fin, la pedagogía de Don Bosco se ha generado desde las circunferencias de su sacerdocio, que ha sido el inspirador sucesivo de todas sus iniciativas, probablemente inexplicables sin él. Con una propuesta de modelos concretos, el santo se dirigía a los muchachos en uno de sus libritos así, directo e imparable:

Decid en vuestro corazón lo que decía san Agustín: Si ille, cur non ego? Si un compañero mío, de mi misma edad, en el mismo lugar, expuesto a los mismos y tal vez mayores peligros, encontró sin embargo, tiempo y modo de mantenerse fiel seguidor de Jesucristo, ¿por qué no puedo también yo hacer lo mismo? Recordad que la religión verdadera no consiste solo en palabras; hay que ir a las obras. Por tanto, cuando encontréis alguna cosa digna de admiración, no os contentéis con decir esto es bonito, esto me gusta. Decid más bien: quiero empeñarme para hacer esas cosas que leídas de otros, despiertan mi admiración •

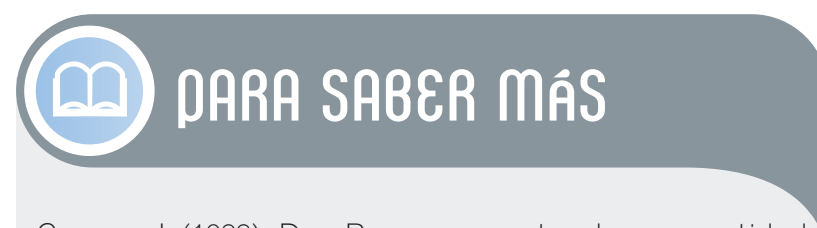

Guerra, J. (1988). Don Bosco, promotor de una santidad juvenil. Misión Joven (132-133), 27-39.

Javierre, A. M. (1976). El pastorcillo de 'I Becchi'". En Cristo palabra y palabra de Cristo (pp. 195-212). Guatemala.

Revuelta, M. (1988). San Juan Bosco, un modelo de pertenencia a la Iglesia. Sal Terrae, 76, 371-379.

Rodríguez de Coro, F. (Ed.). (1990). Don Bosco, maestro de espiritu. Cartas Pastorales de los obispos españoles con motivo del centenario de la muerte de San Juan Bosco (1988-1989). Madrid: CCS.

Rodríguez de Coro, F. (2015). Juan Bosco. Si tienes un sueño realízalo. Prólogo de Óscar Andrés, cardenal Rodríguez Maradiaga. Madrid. 